\title{
Assessing DASS-42 Models among Polytechnic Staff
}

\author{
A. A. Adetunji*, J. A. Ademuyiwa \\ Department of Statistics, Federal Polytechnic, Ile-Oluji, Nigeria \\ Email: *adeadetunji@fedpolel.edu.ng
}

How to cite this paper: Adetunji, A.A. and Ademuyiwa, J.A. (2019) Assessing DASS-42 Models among Polytechnic Staff. Open Access Library Journal, 6: e5334. https://doi.org/10.4236/oalib.1105334

Received: March 13, 2019

Accepted: October 20, 2019

Published: October 23, 2019

Copyright (C) 2019 by author(s) and Open Access Library Inc.

This work is licensed under the Creative Commons Attribution International License (CC BY 4.0).

http://creativecommons.org/licenses/by/4.0/

\begin{abstract}
The DASS-42 is examined among randomly selected staff of the Federal Polytechnic, Ile-Oluji, Nigeria with each respondent (based on their experience in the last one week) choosing between each score $(0,1,2,3)$ for depression, anxiety and stress. Results revealed that junior administrative staff are the most depressed, most stressed and most anxious; senior administrative staff are the least stressed and least anxious while academic staff are the least depressed. Results also show that there is a significant difference in the depressions and anxiety levels of staff in the various categories while the disparities observed in the stress level are not significant. Staff with lowest educational qualification are ranked first in depressions, anxiety and stress level. There is no significant difference between genders, although male staff are marginally more depressed and stressed than female staff while female staff are more anxious than male staff. Results also reveal that depressions, anxiety and stress decrease as age increases; this may be due to satisfaction deriving in life as one gets older and the need to accept fate as one experiences more about life.
\end{abstract}

\section{Subject Areas}

Sociology

\section{Keywords}

Anxiety, DASS-42, Depression, Scale, Stress, Polytechnic, Staff

\section{Introduction}

Anxiety and depression are psychiatric disorders that usually affect about 1 in every 15 people each year world over and about $13 \%$ of people during a lifetime [1]. Depression among many other mental disorders is ranked among first 20 leading causes of disability worldwide and around one-fifth of children across 
the world suffer from one form of mental disorder or another [2]. Many authors have defined stress various ways; with all the definition expressing different views and understanding based on individual perception of the events, or condition causing the stress. According to [3] events and circumstances must be interpreted as threat to the wellbeing of an individual before stress manifest; they defined stress as "a process involving a person's interpretation and response to threatening events and circumstances". Hence, stress is appropriately related to events and conditions that are interpreted by individuals as producers of discomforts which affect the attainment of their stated objectives, duties and responsibilities. Also, [4] sees stress as "a form of hardship, strain, adversity or affliction characterized by force and pressure on person's organ or mental powers". This presupposes that an event which is hard to execute and which also exerts much pressure on an individual is stressful.

The tripartite of stress, anxiety and depression are the number one diagnosed psychology disorder in working people [5] [6]. These disorders may ultimately incapacitate the affected populace in discharging expected responsibilities.

Job stress is the harmful physical and emotional responses that occur when the requirements of the job do not match the capabilities, resources, or needs of the worker. When an individual is stressed out, the body responds by raising the concentration of stress hormones in the blood and when the body continues to respond to constant demands or threats, coping mechanisms stay in overdrive, which can be damaging to health over time. Excessive job stress can lead to many long-term health problems, including cardiovascular disease, diabetes, weakened immune function, high blood pressure, musculoskeletal disorders, substance abuse, depression and anxiety.

Stressful working conditions can impact health indirectly by limiting the ability or motivation to participate in other health promoting behaviors such as eating well and exercising [7]. Stress at job varies based on the job set-up and responsibilities of the workers, usually; people at the lower level of management in official settings tend to be more stress physically while the mental stress is usually felt by those at the upper management position.

Work-related stress causes negative emotional state which can lead to both physical and mental illness if it persists. On the basis on gender, age, type of organization and other socio-demographic variables, the amount of anxiety can differ from an individual to the other [8]. When exposed to the same conditions, [9] revealed that females are more likely to report symptomology associated with fatigue, pain, digestive problems and several psychomotor agitations and confusions compared to their male counterparts. Also, [10] [11] reported a significant difference between female and male police officers with female officers having higher level of depression, anxiety, and stress. Other researchers [12] [13] [14] have shown that women are more anxious and suffer more stress than men when exposed to the same conditions.

In higher institution set up, there are academic staff, senior administrative staff and junior administrative staff. Although, stress, anxiety and depression 
had been assessed along with various variables, there no reported literature assessing differences among classes of workforce in higher institution. Among these three categories of workers, it is assumed that physical stress will be felt more among junior staff while senior staff are expected to suffer more metal stress.

Depression, anxiety and stress have been opined to progress as one gets older. Older workers in Britain have consistently shown unwillingness to remain in labour force [15] largely due to associated old-age illness.

Ideally, a stress free working condition for staff of any organization is a "sine qua non" for an improved job performance on the job. This is because such conditions are characterized by availability of job resources capable of fulfilling the basic human needs for psychological competence that in-turn enhances the overall wellbeing and increased motivation. To this end, job resources, namely: institutional support (including relationship with superiors, role clarity, information, communication and participation); growth opportunities (including variety, opportunity to learn and autonomy); social support and advancement are positively related to a free stress working condition for staff. This study is aimed at gaining an accurate and subjective assessment of the severity of depression, anxiety, and/or stress levels among polytechnic staff using the depression, anxiety, and stress scale (DASS 42) along with some socio-demographic variables (Sex, Educational qualifications, Unit, and Age). The output of the research is expected to help management to appropriately develop and assist in resolving depressive, anxiety, and/or stress-related symptoms among the staff.

\section{Materials and Methodology}

In this paper, the DASS-42 is examined among randomly selected staff of the Federal Polytechnic, Ile-Oluji, Nigeria with each respondent (based on their experience in the last one week) choosing between each score $(0,1,2,3)$ for depression, anxiety and stress. The respondents include 126 males and 74 females staff with age distribution $(20-29$ years $=34,30-39$ years $=113,40-49$ years $=$ 40 , and 50 years and above $=13$ ). 47 of them are Academic staff, 113 are Senior Administrative staff while 40 are junior administrative staff.

\section{Measures}

The depression anxiety stress scales (DASS) is a respondent self-reporting tool for assessing severity of the negative emotional states of depression, anxiety, or stress symptoms [16]. The scale from the creation of two subscales is designed by [17] to measure depression and anxiety. The original items were uniquely designed to differentiate between symptoms of anxiety and depression, where items that are not related to neither depression nor anxiety were used as control [18]. Respondents must be at least 12 years and the responses must be based on assessment for depression, anxiety, and stress symptoms within a week. The 
DASS is a measuring tool (not a diagnosing tool) and it is developed not to serve as a comprehensive bio-psychosocial assessment instrument. The depression subscale appraises hopelessness, life devaluation, lack of involvement/interest, self-deprecation and inactiveness while the stress subscale scale measures relaxing difficulty, easiness of upsetting, levels of inveterate non-specific stimulation and impatient. The anxiety subscale evaluates situational anxiety, arousal, effects of skeletal muscle, and immanent experience.

The instrument generally assesses for depression, anxiety, and stress with the use of a subscale for each of the three categories, each containing 14 items. On each subscale, the DASS score ranges from $0-42$ and the total score is obtained by summing the scores for each subscale.

The items for each subscale and the standard indications for interpretations are given in Table 1 .

Items on the depression subscale are $3,5,10,13,16,17,21,24,26,31,34,37$, 38 , and 42 . The anxiety subscale has items $2,4,7,9,15,19,20,23,25,28,30,36$, 40 , and 41 while the stress subscale has items $1,6,8,11,12,14,18,22,27,29,32$, 33,35 , and 39.

[16] reported that people with at least moderate depression are at increased risk for suicide and require immediate referral to a mental health professional for prompt assessment and treatment.

The DASS provides information on respondent's report on low mood, self-esteem, irritability, panic, motivation, and fear [16]. Based on the score obtained from DASS assessment, respondents with signs and symptoms of depression may be referred to further psychometric evaluation.

Total score for each subscale is obtained for all the respondents and the scores obtained were analyzed using the IBM Statistical Package for Social Sciences (version 23). At 5\% significant level, t-test is applied to measure the differences in the levels of depression, anxiety and stress between female and male staff while ANOVA was used to test or significant difference among staff in the different 1) Units (Academic, Senior and Junior Administrative); 2) Educational level and 3) Age group.

\section{Results}

\section{Reliability}

Reliability comes to the forefront when variables developed from summated scales are used as predictor components in objective models; it tests how well a test consistently measures what it is supposed to measure. The mostly reported measurement tool is the Cronbach's alpha developed by [19]. However recent reviews [20] had shown that there are better estimates of reliability like McDonald's $\omega_{t}[21]$. In view of this, the internal consistency of the factors was observed using the psych package from CRAN [22]. The obtained estimate of reliability for the entire DASS 42 is 0.95 . The reliability coefficient for depression subscale is 0.89 ; anxiety subscale is 0.85 and for stress subscale is 0.86 (Table 2). 
Table 1. DASS indicators.

\begin{tabular}{cccccc}
\hline & Normal & Mild & Moderate & Severe & Very Severe \\
\hline Depression & $0-9$ & $10-13$ & $14-20$ & $21-27$ & $\geq 28$ \\
Anxiety & $0-7$ & $8-9$ & $10-14$ & $15-19$ & $\geq 20$ \\
Stress & $0-14$ & $15-18$ & $19-25$ & $26-33$ & $\geq 34$
\end{tabular}

Source: [17].

Table 2. Descriptive statistics and ANOVA values of DASS among the units.

\begin{tabular}{|c|c|c|c|c|c|c|}
\hline & & Mean & Standard & Std. Dev. & $\mathrm{F}_{\text {-critical }}$ & $\mathrm{P}_{\text {-value }}$ \\
\hline \multirow{4}{*}{ Depressions Sum } & Academic & 7.02 & Normal & 6.595 & \multirow{4}{*}{5.773} & \multirow{4}{*}{0.004} \\
\hline & Senior Admin & 7.76 & Normal & 7.561 & & \\
\hline & Junior Admin & 11.98 & Mild & 8.207 & & \\
\hline & Total & 8.43 & Normal & 7.660 & & \\
\hline \multirow{4}{*}{ Anxiety Sum } & Academic & 8.38 & Mild & 6.964 & \multirow{4}{*}{4.372} & \multirow{4}{*}{0.014} \\
\hline & Senior Admin & 7.53 & Mild & 6.684 & & \\
\hline & Junior Admin & 11.23 & Moderate & 6.900 & & \\
\hline & Total & 8.47 & Mild & 6.908 & & \\
\hline \multirow{4}{*}{ Stress Sum } & Academic & 10.40 & Normal & 7.450 & \multirow{4}{*}{2.257} & \multirow{4}{*}{0.079} \\
\hline & Senior Admin & 9.37 & Normal & 7.338 & & \\
\hline & Junior Admin & 12.40 & Normal & 6.964 & & \\
\hline & Total & 10.22 & Normal & 7.349 & & \\
\hline
\end{tabular}

Source: [17].

With the average score of 7.53 and 9.37, Table 3 reveals that the senior administrative staff are the least anxious and stressed respectively while the academic staff are the least depressed. Junior administrative staff are consistently most depressed, anxious and stressed, though the levels are not severe.

While there is no significant difference in the stress level of staff in the various categories, both depressions and anxiety levels are significantly difference. Using Tukey's HSD Post Hoc test for homogeneous subsets, it is revealed that both Academic and Senior administrative staff have no significant difference in the depressions and anxiety levels.

Though, depressions, anxiety and stress level is highest for staff with only primary education, there is no significant difference for depression and anxiety among various educational qualifications. There is however a significant difference in the stress level of the staff with post hoc test revealing difference in the stress level of staff with only Primary school education and staff with other qualifications.

Table 4 reveals slightly higher averages for male staff than female in all factors under consideration. Although [8] had reported that depression, anxiety and stress can differ from an individual to another depending on the type of organization, 
Table 3. Descriptive statistics and ANOVA of DASS for different educational qualifications.

\begin{tabular}{|c|c|c|c|c|c|c|}
\hline & & Mean & Standard & Std. Dev. & $\mathrm{F}_{\text {-critical }}$ & $\mathrm{P}_{\text {-value }}$ \\
\hline \multirow{4}{*}{ Depressions Sum } & Primary & 11.75 & Mild & 8.808 & \multirow{4}{*}{0.482} & \multirow{4}{*}{0.618} \\
\hline & Secondary & 7.30 & Normal & 3.164 & & \\
\hline & Post-Secondary & 8.42 & Normal & 7.815 & & \\
\hline & Total & 8.43 & Normal & 7.660 & & \\
\hline \multirow{4}{*}{ Anxiety Sum } & Primary & 12.75 & Moderate & 1.708 & \multirow{4}{*}{0.912} & \multirow{4}{*}{0.403} \\
\hline & Secondary & 7.30 & Mild & 3.592 & & \\
\hline & Post-Secondary & 8.44 & Mild & 7.084 & & \\
\hline & Total & 8.47 & Mild & 6.908 & & \\
\hline \multirow{4}{*}{ Stress Sum } & Primary & 19.75 & Moderate & 5.560 & \multirow{4}{*}{3.607} & \multirow{4}{*}{0.029} \\
\hline & Secondary & 9.10 & Normal & 4.725 & & \\
\hline & Post-Secondary & 10.08 & Normal & 7.380 & & \\
\hline & Total & 10.22 & Normal & 7.349 & & \\
\hline
\end{tabular}

Table 4. Descriptive statistics and t-test values of DASS for genders.

\begin{tabular}{ccccccc}
\hline & & Mean & Standard & Std. Dev. & $\mathrm{t}_{\text {-critical }}$ & $\mathrm{P}_{\text {-value }}$ \\
\hline \multirow{3}{*}{ Depressions Sum } & Male & 8.67 & Normal & 7.921 & & \\
& Female & 8.03 & Normal & 7.230 & 0.569 & 0.570 \\
& Total & 8.43 & Normal & 7.660 & & \\
Anxiety Sum & Male & 8.82 & Mild & 7.292 & & \\
& Female & 7.88 & Mild & 6.202 & 0.928 & 0.355 \\
& Total & 8.47 & Mild & 6.908 & & \\
Stress Sum & Male & 10.41 & Normal & 7.757 & & \\
& Female & 9.89 & Normal & 6.636 & 0.483 & 0.630 \\
& Total & 10.22 & Normal & 7.349 & & \\
\hline
\end{tabular}

gender and age, the result opposes views of police samples [10] [11] [23] [24] where female officers are reported to suffer higher level of stress, anxiety and depression in comparison with their male counterparts. Assessing stress among university workers, [25] also found that male teachers stress in comparison to the opposite gender. In support of the finding by [26], independent sample t-test however shows that there is no significant difference in the three subscales (depression, anxiety and stress) between male and female staff.

Table 5 reveals a steady reduction in depression, anxiety and stress as ages of the workers increase. This observation supports the report of [27] among college teachers. Analysis of variance among the age group also indicates a significant difference with Tukey's HSD post-hoc test revealing a more significant difference as ages differ. 
Table 5. Descriptive statistics and ANOVA values of DASS for different age groups.

\begin{tabular}{|c|c|c|c|c|c|c|}
\hline & & Mean & Standard & Std. Dev. & $\mathrm{F}_{\text {-critical }}$ & $\mathrm{P}_{\text {-value }}$ \\
\hline \multirow{5}{*}{ Depressions Sum } & $20-29$ & 11.79 & Mild & 8.693 & \multirow{5}{*}{3.413} & \multirow{5}{*}{0.019} \\
\hline & $30-39$ & 8.30 & Normal & 7.328 & & \\
\hline & $40-49$ & 6.73 & Normal & 7.355 & & \\
\hline & $50 \&$ above & 6.00 & Normal & 6.325 & & \\
\hline & Total & 8.43 & Normal & 7.661 & & \\
\hline \multirow{5}{*}{ Anxiety Sum } & $20-29$ & 12.06 & Mild & 7.912 & \multirow{5}{*}{4.818} & \multirow{5}{*}{0.003} \\
\hline & $30-39$ & 8.33 & Mild & 6.379 & & \\
\hline & $40-49$ & 6.43 & Normal & 5.918 & & \\
\hline & $50 \&$ above & 6.63 & Normal & 8.441 & & \\
\hline & Total & 8.47 & Mild & 6.908 & & \\
\hline \multirow{5}{*}{ Stress Sum } & $20-29$ & 13.38 & Normal & 8.631 & \multirow{5}{*}{4.320} & \multirow{5}{*}{0.006} \\
\hline & $30-39$ & 10.43 & Normal & 6.602 & & \\
\hline & $40-49$ & 7.95 & Normal & 7.292 & & \\
\hline & $50 \&$ above & 7.23 & Normal & 7.463 & & \\
\hline & Total & 10.22 & Normal & 7.349 & & \\
\hline
\end{tabular}

\section{Conclusions}

A stress-free working condition for the staff of any organization is a "sine qua non" for an improved job performance which will lead to a better productivity. Consequently, from the analysis and interpretation of the collected data, results revealed that junior administrative staff are the most depressed, most stressed and most anxious when compared with other categories of staff working in the polytechnic. Senior administrative staff are the least stressed and least anxious while academic staff are the least depressed.

Results also show that there is a significant difference in the depressions and anxiety levels of staff in the various categories while the disparities observed in the stress level are not significant.

Staff with lowest educational qualification are ranked first in depressions, anxiety and stress level, though the difference is not statistically significant for depression and anxiety, there is a significant difference in the stress level of the staff with post hoc test revealing difference in the stress level of staff with only Primary school education and staff with other qualifications.

Although, there is no significant difference between genders, male staff are marginally more depressed and stressed than female staff while female staff are more anxious than male staff.

Results also reveal that depressions, anxiety and stress decrease as age increases; this may be due to satisfaction derive in life as one gets older and the need to accept fate as one experiences more about life.

\section{Conflicts of Interest}

The authors declare no conflicts of interest regarding the publication of this paper. 


\section{References}

[1] Steel, Z., Marnane, C., Iranpour, C., Chey, T., Jackson, J.W., Patel, V. and Silove, D. (2014) The Global Prevalence of Common Mental Disorders: A Systematic Review and Meta-Analysis 1980-2013. International Journal of Epidemiology, 43, 476-493. https://doi.org/10.1093/ije/dyu038

[2] World Health Organisation (2008) The Global Burden of Disease 2004 Update.

[3] Aureback, S. and Gramling, K. (2009) Psychology, Encarta Encyclopedia. Microsoft Corporation, New York.

[4] Cooper, C. and Marshall, J. (2007) The Experience of Work Related Stress across Occupation. Journal of Managerial Psychology, 20, 56-82.

[5] Brown, T., Chorpita, B., Korotitsch, W. and Barlow, D. (1997) Psychometric Properties of the Depression Anxiety Stress Scales (DASS) in Clinical Samples. Behavior Research and Therapy, 35, 79-89. https://doi.org/10.1016/S0005-7967(96)00068-X

[6] Farmer, R. (1998) Depressive Symptoms as a Function of Trait Anxiety and Impulsivity. Journal of Clinical Psychology, 54, 129-135.

https://doi.org/10.1002/(SICI)1097-4679(199802)54:2<129::AID-JCLP1>3.0.CO;2-N

[7] World Health Organisation (2014) Mental Disorders.

[8] Morteza, A. and Morteza, S.P.V. (2014) International Conference on Current Trends in ELT an Investigation of Teaching Anxiety among Novice and Experienced Iranian EFL Teachers across Gender.

[9] Bitsika, V., Sharpley, C.F. and Melhem, T.C. (2010) Gender Differences in Factor Scores of Anxiety and Depression among Australian University Students: Implications for Counselling Interventions. Canadian Journal of Counselling, 44, 51-64.

[10] Husain, W., Sajjad, R. and Rehman, A. (2014) Depression, Anxiety and Stress among Female and Male Police Officers. Pakistan Journal of Clinical Psychology, 13, 3-14.

[11] He, N., Zhao, J. and Ren, L. (2005) Do Race and Gender Matter in Police Stress? A Preliminary Assessment of the Interactive Effects. Journal of Criminal Justice, 33, 535-547. https://doi.org/10.1016/j.jcrimjus.2005.08.003

[12] Matud, M.P. (2004) Gender Differences in Stress and Coping Styles. Personality and Individual Differences, 37, 1401-1415. https://doi.org/10.1016/j.paid.2004.01.010

[13] Baruch, G.K., Biener, L. and Barnett, R.C. (1987) Women and Gender in Research on Work and Family Stress. American Psychologist, 42, 130-136. https://doi.org/10.1037/0003-066X.42.2.130

[14] Mirowsky, J. and Ross, C.E. (1995) Sex Differences in Distress: Real or Artifact? American Sociological Review, 60, 449-468. https://doi.org/10.2307/2096424

[15] Griffiths, A., Knight, A. and Mahudin, A.M. (2009) Ageing, Work-Related Stress and Health: Reviewing the Evidence. A Report for Age Concern and Help the Aged and TAEN (The Age and Employment Network).

[16] Gale, L. (2015) Anxiety and Depression Assessment: Using the Depression Anxiety Stress Scales, Cinahl Information Systems, a Division of EBSCO Information Services.

[17] Lovibond, S.H. and Lovibond, P.F. (1995) Manual for the Depression Anxiety and Stress Scale. Second Edition, Psychology Foundation, Sydney.

[18] Crawford, J.R. and Henry, J.D. (2003) The Depression Anxiety Stress Scale (DASS): Normative Data and Latent Structure in a Large Non-Clinical Sample. British Journal of Clinical Psychology, 42, 111-131. 
https://doi.org/10.1348/014466503321903544

[19] Cronbach, L.J. (1951) Coefficient Alpha and the Internal Structure of Tests. Psychometrika, 16, 297-334. https://doi.org/10.1007/BF02310555

[20] Sijtsma, K. (2008) On the Use, the Misuse, and the Very Limited Usefulness of Cronbach's Alpha. Psychometrika, 74, 107-120. https://doi.org/10.1007/s11336-008-9101-0

[21] McDonald, R.P. (1999) Test Theory: A Unified Treatment. Erlbaum, Hillsdale.

[22] Revelle, W. (2008) Psych: Procedures for Personality and Psychological Research (R Package Version 1.0-51).

[23] Daniela, V. (2011) Stress and Job Satisfaction among University Teachers. International Conference of Scientific Paper AFASES, Brasov, 26-28 May 2011, 320-325.

[24] Violanti, J.M., Desta, F., Luenda, E., Charles, M.E., Andrew, T.A., Anna, M. and Cecil, M. (2008) Suicide in Police Work: Exploring Potential Contributing Influences. American Journal of Criminal Justice, 34, 41-53. https://doi.org/10.1007/s12103-008-9049-8

[25] Varda, P. and Akhtar, S. (1989) A Study of Extra Organizational Stress. National Seminar on Anxiety, Stress and Depression in Modern Life, Patiala, November 1989.

[26] Putter, L. (2003) Stress Factors among Teachers in Schools of Industry. Unpublished M.A. Thesis, University of Zululand, Zululand.

[27] Kumar, D. and Deo, J.M. (2011) Stress and Work Life of College Teachers. Journal of the Indian Academy of Applied Psychology, 37, 78-85. 